\title{
3 Research Square

\section{Metabolomic Analysis of Skin Malodor-Associated Compounds and Structure-based Prediction of Acetolactate Synthase Selective Sulfonylurea Inhibitors}

Ryan Yuki Huang ( $\square$ rhuang53@gmail.com )

University of California, San Diego

\section{Research Article}

Keywords: Acetolactate synthase, Metabolites, Repurposing, Skin malodor, Sulfonylureas

Posted Date: December 23rd, 2021

DOI: https://doi.org/10.21203/rs.3.rs-1193756/v1

License: (c) (i) This work is licensed under a Creative Commons Attribution 4.0 International License. Read Full License 


\section{Abstract}

Bromhidrosis is characterized as a chronic condition related to malodor from the skin. The underlying etiology is from bacterial decompositions of glandular secretion products. However, specific pathways and metabolites for the disease are yet to be investigated. Here, twenty-eight metabolites, including fifteen major sweat constituents and thirteen compounds emitted from malodor-producing skin bacteria, were subjected to the metabometric analysis using Metaboanalyst. Different pathways in the butanoate metabolism revealed that acetolactate synthase (ALS) in skin Staphylococcus epidermidis (S. epidermidis) bacteria are catalyzing pyruvate to several malodor compounds like diacetyl. In the docking studies of the sulfonylurea-ALS interaction, five selected sulfonylureas, which originally were developed for the treatment of diabetes mellitus type 2 , showed different binding free energies $(\Delta G)$ from chlorimuron ethyl - a well-known ALS sulfonylurea inhibitor. Amongst five sulfonylureas, gliquidone and glisoxepide were found to have free energy differences that were lower than or equal to chlorimuron ethyl, revealing their high affinities to ALS. In the future, further investigations of gliquidone and glisoxepide against ALS in skin bacteria would be crucial in repurposing these two sulfonylureas as new antibromhidrosis drugs.

\section{Introduction}

The term, skin microbiome, has been commonly defined as the collection of microorganisms that reside on our skin. There are approximately one thousand species in the skin microbiome from nineteen different phyla. Bacterial species, in particular, make up four phyla, composed of approximately 51.8\% Actinobacteria, 24.4\% Firmicutes, 16.5\% Proteobacteria, and 6.3\% Bacteroidetes. Three of the most frequently studied skin bacterial species include Staphylococcus spp., Cutibacterium spp., and Corynebacterium spp. (1). Notably, Staphylococcus epidermidis (S. epidermidis), Staphylococcus aureus (S. aureus), Staphylococcus warneri (S. warnieri), Cutibacterium acnes (C. acnes), and Corynebacterium aurimucosum (C. aurimucosum) are best studied bacterial species in human skin, although $16 \mathrm{~S}$ ribosomal RNA research finds these species comprise less than $10 \%$ of skin bacteria (2).

Skin bacteria can utilize endogenous carbohydrates or amino acids on the skin to undergo glycolysis and amino acid metabolism, producing energy and other metabolites that are essential for their growth. They also trigger the fermentation process and convert carbohydrates or amino acids to short-chain fatty acids (SCFAs) and other metabolites. These include primary metabolites, which are vital for the proper growth of bacteria. They also include secondary metabolites - like antibiotics, pigments, growth hormones, antitumor agents, and others - that are not needed for the growth and development of bacteria but hold great potential for human health (3). Microorganisms are known to produce plentiful secondary metabolites, being exploited as useful bioactive molecules. Several skin bacteria have been used to obtain biologically active compounds like SCFAs (4), peptides (5), carbohydrates, and fatty acids, that benefit humans to combat various skin diseases. However, some secondary metabolites are toxic, which can enhance bacterial virulence (6). Several secondary metabolites - including diacetyl or 2,3butanedione, a by-product of lactate - are derived from protein breakdown within sweat by skin bacteria 
can lead to bromhidrosis, a chronic condition in which excessive malodor can have adverse effects on a person's quality of life (7).

In humans, the formation of malodors results from many factors such as diet and inherited conditions. However, the decomposition of skin metabolites by skin bacteria is one of the key factors that contribute to malodors. Human sweat is mainly produced as the secretion from eccrine and apocrine glands. The constituents of sweats on the skin were composed of metabolites originally from either humans or skin bacteria. Although humans and skin bacteria share common pathways to produce or degrade constituents in sweats, skin bacteria express several unique enzymes that can metabolize sweat constituents (8). Laser interference and surgery to destroy subcutaneous apocrine sweat glands are the most commonly used treatments for body malodors (9). The use of aluminum antiperspirant is able to block the sweat glands to keep sweat from getting to the skin's surface (10). However, both removal of sweat glands by surgery and blockage of sweat glands by aluminum antiperspirant cannot terminate the malodor production derived from the metabolism of bacteria on the skin. Furthermore, the side-effects, including osteomalacia and microcytic anemia, caused by the accumulation of aluminum on human tissues have been extensively reported (11). Reduction in malodor formation can be achieved by the use of antimicrobial antiperspirants which contain tricolsan (10) to kill skin bacteria inducing S. epidermidis and Corynebacterium spp. However, non-special killing skin bacteria by these antimicrobial antiperspirants may completely disrupt the beneficial bacteria in the skin microbiome (12).

Antiperspirants with substances, which can specifically inhibit bacterial enzymes responsible for the production of skin malodors, may be an alternative modality to treat bromhidrosis. In this study, we employ bioinformatics approaches to distinguish the metabolic pathways of sweat constitutes in humans and skin bacteria and predict the three-dimensional (3-D) structures of the interaction of bacterial enzyme and its commercial inhibitors. Repurposing these commercial inhibitors of bacterial enzymes hold tremendous potential for the development of next-generation antiperspirants, which specially target the bacterial metabolic pathway of producing body malodors.

\section{Methods}

\section{Pathway analysis}

Metaboanalyst version 5.0 was used to perform the pathway analysis (https:// www.metaboanalyst.ca) (13). All metabolites with identification of the human metabolome database (HMDB ID) were uploaded onto the Metaboanalyst version 5.0 as a compound list. The KEGG (Kyoto Encyclopedia of Genes and Genomes) of Homo sapiens or prokaryotes (Staphylococcus aureus N315) was selected for pathway matching. All matched pathways were according to the $p$-values from the pathway enrichment analysis and pathway impact values from the pathway topology analysis. The p-values less than 0.05 for pathway matching were considered significant. The pathways of butanoate metabolism (14) in homo sapiens and S. epidermidis ATCC 12228 were compared.

\section{Acetolactate synthase (ALS)-inhibitor docking}


The Guru interface of High Ambiguity Driven protein-protein Docking (HADDOCK)2.2 webserver (https://alcazar.science.uu.nl/services/HADDOCK2.2/) was used for calculating ALS-inhibitor docking. The crystal structure of chain A in the catalytic subunit of Saccharomyces cerevisiae ALS [Identify number (ID) 6U9D], also known as acetohydroxyacid synthase (AHAS) (15) was obtained from Protein Data Bank (PDB). The 3-D structures of inhibitors in the structure-data file (SDF) retrieved from PubChem were converted to PDB formats via Open Babel software. ALS in complex with its inhibitors was refined in HADDOCK2.2 and subsequently scored. The docking procedure was conducted performed in steps: randomization and rigid body energy minimization, semi-flexible simulated annealing, and flexible explicit solvent refinement. 10,000, 400, and 400 structures for rigid-body docking, semiflexible refinement, and explicit solvent refinement were used as parameters (16). The root means square deviation (RMSD)-based clustering with $2.0 \AA$ cutoff was conducted. The change in Gibbs free energy $(\triangle \mathrm{G})(\mathrm{Kcal} / \mathrm{mol})$ of binding and interacting residues were calculated and determined for each ALSinhibitor interaction using PRODIGY (PROtein binDIng enerGY prediction) (https://wenmr.science.uu.nl/prodigy/). PyMOL (17) was used for structural representations.

\section{Results}

Through the metabolism of amino acids, many skin bacteria produced odor molecules as primary metabolites such as acetic acid, butyric acid, isovaleric acid (18). Citric acid, formic acid, and furmaric acid as primary metabolites produced from glycolysis of skin bacteria also carry unpleasant odors. In the absence of oxygen, skin bacteria produced secondary metabolites through the fermentation of carbohydrates or amino acids. Ethylmethylacetic acid, isobutyric acid, and valeric acid produced from carbohydrate fermentation of skin bacteria are volatile compounds that naturally give rise to odors. It has been reported that commensal skin $S$. epidermidis bacteria can yield a detectable amount of diacetyl, also called 2,3-butanedione (19), a key contributor to malodors emanating from the axillae, feet, and head regions. The production of 3-methylindole (skatole) by bacterial fermentation of the amino acid tryptophan generated bad odors (20). Besides fermentation, odor molecules in the secondary metabolites can be produced via the gene activation or secretion systems of various microorganisms in the skin. Both $C$. acnes and $S$. warneri have the $\beta$-glucuronidase activities to increase androstenol (5alpha-Androst-16en-3alpha-ol) in sweat odors (21). Corynebacterium spp. converted testosterone to $5 \mathrm{~b}$ dihydrotestosterone in the axilla (22).

While sweat itself is virtually odorless, skin bacteria can break down the constituents in sweat to release the smell. To examine how skin bacteria and humans metabolize sweat constituents, 28 metabolites including 13 odor metabolites of skin bacteria and 15 major sweat constituents (>0.26 mM) (23) were pooled as a compound list (Table 1) and uploaded onto Metaboanalyst version 5.0 for pathway analysis. A p-value of 0.05 was accepted as the threshold to determine whether a pathway is significantly impacted. In humans, eight matched pathways were considered to have significant roles in metabolizing 28 selected metabolites. These matched pathways were aminoacyl-tRNA biosynthesis, alanine, aspartate and glutamate metabolism, glyoxylate and dicarboxylate metabolism, citrate cycle, pyruvate metabolism, arginine biosynthesis, phenylalanine, tyrosine and tryptophan biosynthesis, and butanoate (butryric acid) 
metabolism. In prokaryotes, when S. aureus N315 was chosen, ten pathways including eight matched pathways present in humans, taurine and hypotaurine metabolism, and methane metabolism have pvalues less than 0.05 .

Both beneficial and harmful effects of butyric acid on humans have been documented (24). Thus, we examined how butanoate metabolism in humans or skin bacteria metabolized 28 constituents detectable in sweat. Axilla with many sweat glands is dominated by S. epidermidis, a bacterial strain exhibiting strong underarm malodors in humans (25). The butanoate metabolisms in S. epidermidis and humans were compared. As shown in Figure 1, S. epidermidis and humans expressed many different enzymes to metabolize 28 selected metabolites (Table 1). There were three enzymes that were expressed in both $S$. epidermidis and humans in bantanoate metabolism for synthesis or degradation of 28 selected metabolites. These three enzymes were acetyl-CoA C-acetyltransferase (EC 2.3.1.9), hydroxymethylglutaryl-CoA synthase (EC 2.3.3.10), and 4-aminobutyrate-2-oxoglutarate transaminase (EC 2.6.1.19). A pathway for the formation of diacetyl, 2-acetonin, and butane-2,3-diol, odor compounds in axillae, was exclusively present in S. epidermidis, not humans. S. epidermidis can mediate carbohydrate fermentation to produce diacetyl, 2-acetonin, and butane-2,3-diol. The ALS (EC 2.2.1.6) is an enzyme in the initial step to convert pyruvate to those odor compounds during bacterial carbohydrate fermentation. Inhibition of the activity of ALS in skin bacteria may be able to reduce the formation of odor diacetyl, 2-acetonin, and butane-2,3-diol on the skin.

It has been documented that ALS acts as the first enzyme in the biosynthetic pathway of the branchedchain amino acids valine, leucine, and isoleucine (26). The pathway is present in both plants and prokaryotes but does not exist in humans and other animals (27). The crystal structures of Arabidopsis thaliana ALS (AtALS) and Saccharomyces cerevisiae ALS (ScALS) binding with/without various inhibitors have been revealed $(28,29)$. Furthermore, the ALS complex of Mycobacterium tuberculosis shared a similar structure, suggesting that the overall ALS structure is conserved across kingdoms (30). These inhibitors of ALS were ultimately developed as herbicides or antimicrobials (31). The sulfonylureas and imidazolinones as ALS inhibitors with values of inhibition constant (Ki) in the $\mathrm{nM}$ and $\mathrm{mM}$ ranges, respectively, are potent commercial herbicide families (32). The conformation of the sulfonylureas when bound to either ScALS or AtALS is very comparable (29). Since the inhibition of ALS by sulfonylureas has a lower Ki value, we employed the complex of ScALS with chlorimuron ethyl, a highly active sulfonlyures, as a control structure (32) to screen other sulfonylureas.

Initially, sulfonylureas were developed as pharmaceutics for treatment of diabetes. Later, a large number of sulfonylureas including chlorimuron ethyl were used as herbicides. The pharmacological molecules of sulfonylureas are composed of a central S-arylsulfonurea structure with a p-substituent on the phenyl ring and diverse groups terminating the other side of the urea group. Here, we examine the interaction of ALS, catalytic subunit, chain A (30) with five sulfonylurea derivatives (Table 2) which are currently commercially available for treatments of diabetes mellitus type 2 . The binding free energy and amino acids of ALS with five individual sulfonylurea derivatives were determined for the selective identification of the potential inhibitors for ALS. The lesser the binding free energy difference, the better the binding of 
ALS and sulfonylurea will occur. As shown in Figure $2 A$, the value of binding free energy difference $(\Delta G)$ between ALS and chlorimuron ethyl was $-6.6 \mathrm{Kcal} / \mathrm{mol}$. Histidine 599 (HIS599) was the major amino acid in ALS for the binding of chlorimuron ethyl. Three atoms in chlorimuron ethyl in 1.7, 3.1 and $3.2 \AA$ distances, respectively, from HIS99. The $\Delta \mathrm{G}$ values of gliquidone and glisoxepide to ALS were -7.4 and $-6.6 \mathrm{Kcal} / \mathrm{mol}$, respectively, which were lower than or equal to that of chlorimuron ethyl to ALS, demonstrating the high affinity interaction between ALS and gliquidone or glisoxepide. Three sulfonylureas (metahexamide, tolbutamide and chlorpropamide) have higher $\Delta G$ values at $-6.4,-6.3$ and $-6.1 \mathrm{Kcal} / \mathrm{mol}$, respectively, than chlorimuron ethyl. The glutamine (GLN)202, proline (PRO)114, glycine (GLY)116 in ALS were major amino acid residues for gliquidone binding. GLN418 and arginine (ARG)393 in ALS were identified as binding amino acids for glisoxepide. Results in Table 2 unveiled the binding affinity and amino acid binding sites of ALS chain A for anti-diabetic sulfonylureas which hold potential as new ALS inhibitors.

\section{Discussion}

The axillary bacteria play the main role in the generation of malodors such as volatile fatty acids (VFAs), 3-hydroxy hexanoic acid (3M3H), and 3-hydroxy-3-methylhexanoic acid (HMHA) (33) in the human armpit via decomposition of the odorless sweat $(34,35)$. Previous studies have demonstrated that Corynebacterium spp. can produce VFAs, HMHA, 3M2H, and 5a-androst-16-en-3a-ol $(21,33,36)$.

Anaerococcus spp. was a key producer of odorants such as VFAs and 3-hydroxy-3-methylhexanoic acid (37-39). Staphylococcus spp., Micrococcus spp., and Cuitibacterium spp. can produce different types of odor compounds, including VFAs and 3-methyl-3-sulfanylhexan-1-ol $(36,40)$. Staphylococcus hominis (S. hominis) and S. epidermidis strains isolated from Asian populations yielded detectable 3-methyl-3sulfanylhexanol (25). Staphylococcus spp., including S. epidermidis strain, can produce a high amount of odor component diacetyl (19). Human skin provides a habitat for the growth of malodor-producing bacteria. As shown in Figure 1, the butanoate metabolism in either humans or skin bacteria can metabolize the 28 selected skin metabolites in Table 1. However, through the activation of ALS, pyruvate fermentation was the unique pathway in the butanoate metabolism of $S$. epidermidis to produce diacetyl, 2-acetonin and butane-2,3-diol. Suppression of malodor production by inhibiting skin bacterial ALS, which is lacking in humans, could represent a promising strategy against bromhidrosis.

Most ALS contains a catalytic subunit ( $65 \mathrm{kDa}$ ) and a smaller regulatory subunit (9 to $54 \mathrm{kDa})(26)$. Inhibitors of ALS have been developed as herbicides and antimicrobials (27). For example, chlorimuron ethyl, a sulfonylurea herbicide, can effectively inhibit the activity of ALS in plants via directly binding to the catalytic subunit of ALS. It has been reported that developed herbicides that impede ALS are not competitive inhibitors and have no shared binding sites with substrates, suggesting that they bind at a region distinct from the active site (26). Through the structure-based studies of the interaction of chain $A$, the catalytic subunit of ALS (30) with five sulfonylurea derivatives (gliquidone, glisoxepide, metahexamide, tolbutamide, and chlorpropamide) that have been used for the treatment of diabetes mellitus type 2, we found that these five sulfonylurea derivatives bind at amino acid residues that were different from the ones for the binding of substrates including magnesium, flavin-adenine dinucleotide 
(FAD) and thiamine diphosphate (ThDP) (data not shown). The free energy of gliquidone or glisoxepide for ALS binding was lower than or equal to that of chlorimuron ethyl, illustrating gliquidone and glisoxepide as potential inhibitors of ALS in skin bacteria. Although it is unclear whether gliquidone and glisoxepide can penetrate bacterial cell walls to inhibit the activity of ALS, the tolbutamide and glibenclamide, two sulfonylureas, have been known to be able to cross phospholipid bilayer membranes rapidly and effectively by a free-diffusion mechanism (41). Several sulfonylureas such as chlorimuron ethyl and metsuluron methy exert excellent bacteriostatic effects against pathogens bacteria, including Burkholderia pseudomallei, Pseudomonas aeruginosa, and Acinetobacter baumannii via inhibition of ALS (42).

It has been reported that six residues [ARG199, methionine (MET)200, lysin (KLS)256, aspartic acid (ASP)376, ARG377, and tryptophan (TRP)574)] in AtALS are vital for directly interacting with the sulfonylurea herbicides (43). Mutations at amino acid residues [ARG318, alanine (ALA)146, GLN148, MET512, and valine (VAL)513)] in Mycobacterium tuberculosis ALS led to significant herbicide resistance against chlorimuron ethyl (44). The structure of ScALS co-crystallized with chlorimuron ethyl has been revealed (32). Chlorimuron ethyl bound to amino acid residues (TRP586, GLY116 and LYS251) of ScALS entirely blocked the access of ThDP substrate to the active sites. The chlorimuron ethyl forms four hydrogen bonds with two amino acid residues (LYS251 and ARG380) of ScALS. Other contacts of ScALS to chlorimuron ethyl included VAL191, phenylalanine (PHE)201, ARG380 and MET582. It has been reported that mutations at VAL191 and MET582 resulted in the resistance of Escherichia coli ALS to chlorimuron ethyl. In this study, HIS599 in chain A, catalytic subunit of ScALS was identified as an amino acid residue for chlorimuron ethyl (Figure 2A). ScALS (ID:6U9D) is composed of catalytic and regulatory subunits. Each subunit contains multiple chains (30). Other known amino acids such as LYS251 and ARG380 in ScALS for the binding of chlorimuron ethyl were not identified in this study. This may be because chain A alone, not the entire ALS with multiple chains, was employed for docking in HADDOCK2.2. Three amino acids (GLN202, PRO114 and GLY116) in ScALS were identified as binding sites of gliquidone. Two amino acids (GLN418 and ARG393) in ScALS that interacted with glisoxepide. Future works will include the mutational analysis to validate the essential roles of these amino acid residues in the binding of ScALS with gliquidone or glisoxepide.

Drug repurposing has numerous advantages over conventional drug discovery approaches (45). It shortens the developing time, lowers the cost, and reduces the safety risk. The glibenclamide, an antidiabetic sulfonylurea that inhibits ATP-sensitive potassium channels in pancreatic beta cells has been repurposed for the treatment of stroke (46). Potential repurposing of four antidiabetic sulfonylureas (glibenclamide, glisoxepide, gliquidone, and glimepiride) with anti-inflammatory activities for treatment of vaginal candidiasis has been reported (47). Although most antidiabetic sulfonylureas were taken by mouth for the treatment of type 2 diabetes mellitus. Topical glibenclamide with anti-inflammatory activity has been used to promote skin wound healing in mice (48). Further examination of the affinity of gliquidone or glisoxepide towards ALS in skin bacteria may be needed to repurpose two sulfonylureas as novel drugs to reduce the malodors emitted from skin bacteria. 


\section{Summary}

Metabometric analysis indicated that inhibition of ALS in malodor-producing skin bacteria was a means to substantially reduce body odor. Molecule docking using HADDOCK2.2 webserver indicated the value of free energy of the binding gliquidone or glisoxepide to the chain $A$ in the catalytic subunit of ALS is either lower than or equal to that of chlorimuron ethyl to ALS, indicating the high interaction affinity of some amino acids at the catalytic subunit of ALS with gliquidone or glisoxepide. The result suggests that gliquidone and glisoxepide can be prioritized as top candidates in future in vitro and in vivo studies to verify their potential as inhibitor drugs for bromhidrosis therapies.

\section{Declarations}

Competing interests: The authors declare no competing interests.

\section{Acknowledgements}

I am grateful to Dr. Igor Tsigelny and Dr. Valentina L. Kouznetsova at the San Diego Supercomputer Center (SDSU), University of California, San Diego (UCSD) for hosting classes to learn about metabolite analysis during the Research Experience for High School Students (REHS) 2021 Program. I would also like to acknowledge Dr. Jennifer Bhatnagar and her Ph.D. student Kathryn Atherton for teaching me bioinformatic techniques to make this project possible.

Funding: None

\section{References}

1. Cogen AL, Nizet V, Gallo RL (2008). "Skin microbiota: a source of disease or defence?". Br J Dermatol. 158, 442-55. doi:10.1111/j.1365-2133.2008.08437.x.

2. Grice EA, Kong HH, Renaud G, Young AC, Bouffard GG, Blakesley RW, et al. (2008). "A diversity profile of the human skin microbiota". Genome Res. 18, 1043-50. doi:10.1101/gr.075549.107.

3. Ruiz B, Chávez A, Forero A, García-Huante Y, Romero A, Sánchez M, et al. (2010) Production of microbial secondary metabolites: regulation by the carbon source. Crit. Rev. Microbiol. 36, 146-67. doi: 10.3109/10408410903489576.

4. Nakamura K, O'Neill AM, Williams MR, Cau L, Nakatsuji T, Horswill AR, Gallo RL. (2020) Short chain fatty acids produced by Cutibacterium acnes inhibit biofilm formation by Staphylococcus epidermidis. Sci. Rep. 10, 21237. doi: 10.1038/s41598-020-77790-9.

5. Cogen AL, Yamasaki K, Sanchez KM, Dorschner RA, Lai Y, MacLeod DT, et al. (2010) Selective antimicrobial action is provided by phenol-soluble modulins derived from Staphylococcus epidermidis, a normal resident of the skin. J. Invest. Dermatol. 130, 192-200. doi:

10.1038/jid.2009.243. 
6. Wyatt MA, Wang W, Roux CM, Beasley FC, Heinrichs DE, Dunman PM, Magarvey NA. (2010) Staphylococcus aureus nonribosomal peptide secondary metabolites regulate virulence. Science 329, 294-6. doi: 10.1126/science.1188888.

7. Malik AS, Porter CL, Feldman SR. (2021) Bromhidrosis Treatment Modalities: A Literature Review. J. Am. Acad. Dermatol. S0190-9622, 00175-4. doi: 10.1016/j.jaad.2021.01.030.

8. Kuhn F, Natsch A. (2009) Body odour of monozygotic human twins: a common pattern of odorant carboxylic acids released by a bacterial aminoacylase from axilla secretions contributing to an inherited body odour type. J. R. Soc. Interface. 6, 377-92. doi: 10.1098/rsif.2008.0223.

9. Letada PR, Landers JT, Uebelhoer NS, Shumaker PR. (2012) Treatment of focal axillary hyperhidrosis using a long-pulsed Nd:YAG 1064 nm laser at hair reduction settings. J. Drugs Dermatol. 11, 59-63.

10. Oliveira ECV, Salvador DS, Holsback V, Shultz JD, Michniak-Kohn BB, Leonardi GR. (2021) Deodorants and antiperspirants: identification of new strategies and perspectives to prevent and control malodor and sweat of the body. Int. J. Dermatol. 60, 613-619. doi: 10.1111/ijd.15418.

11. Yuan B, Klein MH, Contiguglia RS, Mishell JL, Seligman PA, Miller NL, et al. (1989) The role of aluminum in the pathogenesis of anemia in an outpatient hemodialysis population. Ren. Fail. 11, 91-6. doi: 10.3109/08860228909066949.

12. Urban J, Fergus DJ, Savage AM, Ehlers M, Menninger HL, Dunn RR, Horvath JE. (2016) The effect of habitual and experimental antiperspirant and deodorant product use on the armpit microbiome. PeerJ. 4, e1605. doi: 10.7717/peerj.1605.

13. Marco-Ramell A, Palau-Rodriguez M, Alay A, Tulipani S, Urpi-Sarda M, Sanchez-Pla A, AndresLacueva C. (2018) Evaluation and comparison of bioinformatic tools for the enrichment analysis of metabolomics data. BMC Bioinformatics. 19, 1. doi: 10.1186/s12859-017-2006-0.

14. Wu IW, Lee CC, Hsu HJ, Sun CY, Chen YC, Yang KJ, et al. (2020) Compositional and Functional Adaptations of Intestinal Microbiota and Related Metabolites in CKD Patients Receiving Dietary Protein Restriction. Nutrients. 12, 2799. doi: 10.3390/nu12092799.

15. Lonhienne T, Garcia MD, Fraser JA, Williams CM, Guddat LW. (2017) The 2.0 A X-ray structure for yeast acetohydroxyacid synthase provides new insights into its cofactor and quaternary structure requirements. PLoS One. 12, e0171443. doi: 10.1371/journal.pone.0171443.

16. de Vries SJ, van Dijk ADJ, Krzeminski M, van Dijk M, Thureau A, Hsu V, et al. (2007) HADDOCK versus HADDOCK: New features and performance of HADDOCK2.0 on the CAPRI targets. Proteins 69, 72633. doi:10.1002/prot.21723.

17. Mooers BHM, Brown ME. (2021) Templates for writing PyMOL scripts. Protein Sci. 30,:262-9. doi: 10.1002/pro.3997.

18. Sanchez S, Demain AL. (2008) Metabolic regulation and overproduction of primary metabolites. Microb. Biotechnol. 1, 283-319. doi: 10.1111/j.1751-7915.2007.00015.x.

19. Hara T, Matsui H, Shimizu H. (2014) Suppression of microbial metabolic pathways inhibits the generation of the human body odor component diacetyl by Staphylococcus spp. PLoS One. 9, e111833. doi: 10.1371/journal.pone.0111833. 
20. Le PD, Aarnink AJ, Ogink NW, Becker PM, Verstegen MW. (2005) Odour from animal production facilities: its relationship to diet. Nutr. Res. Rev. 18, 3-30. doi: 10.1079/NRR200592.

21. Starkenmann C, Mayenzet F, Brauchli R, Troccaz M. (2013) 5alpha-Androst-16-en-3alpha-ol beta-Dglucuronide, precursor of 5alpha-androst-16-en-3alpha-ol in human sweat. Chem. Biodivers. 10, 2197-208. doi: 10.1002/cbdv.201300286.

22. Nixon A, Mallet Al, Jackman PJ, Gower DB. (1986) Testosterone metabolism by isolated human axillary Corynebacterium spp.: a gas-chromatographic mass-spectrometric study. J. Steroid. Biochem. 24, 887-92. doi: 10.1016/0022-4731(86)90450-4

23. Kutyshenko VP, Molchanov M, Beskaravayny P, Uversky VN, Timchenko MA. (2011) Analyzing and mapping sweat metabolomics by high-resolution NMR spectroscopy. PLoS One. 6, e28824. doi: $10.1371 /$ journal.pone.0028824.

24. Negari IP, Keshari S, Huang CM. (2021) Probiotic Activity of Staphylococcus epidermidis Induces Collagen Type I Production through FFaR2/p-ERK Signaling. Int. J. Mol. Sci. 22, 1414. doi: 10.3390/ijms22031414.

25. Lam TH, Verzotto D, Brahma P, Ng AHQ, Hu P, Schnell D, et al. (2018) Understanding the microbial basis of body odor in pre-pubescent children and teenagers. Microbiome 6, 213. doi: 10.1186/s40168-018-0588-z.

26. Gedi V, Yoon MY. (2012) Bacterial acetohydroxyacid synthase and its inhibitors-a summary of their structure, biological activity and current status. FEBS J. 279, 946-63. doi: 10.1111/j.17424658.2012.08505.x.

27. Pue N, Guddat LW. (2014) Acetohydroxyacid synthase: a target for antimicrobial drug discovery. Curr. Pharm. Des. 20, 740-53. doi: 10.2174/13816128113199990009.

28. Lonhienne T, Garcia MD, Pierens G, Mobli M, Nouwens A, Guddat LW. (2018) Structural insights into the mechanism of inhibition of AHAS by herbicides. Proc. Natl. Acad. Sci. U S A. 115, E1945-E1954. doi: 10.1073/pnas.1714392115.

29. Wang JG, Lee PK, Dong YH, Pang SS, Duggleby RG, Li ZM, Guddat LW. (2009) Crystal structures of two novel sulfonylurea herbicides in complex with Arabidopsis thaliana acetohydroxyacid synthase. FEBS J. 276, 1282-90. doi: 10.1111/j.1742-4658.2009.06863.x.

30. Lonhienne T, Low YS, Garcia MD, Croll T, Gao Y, Wang Q, et al. (2020) Structures of fungal and plant acetohydroxyacid synthases. Nature 586, 317-321. doi: 10.1038/s41586-020-2514-3.

31. Agnew-Francis KA, Tang Y, Lin X, Low YS, Wun SJ, Kuo A, et al. (2020) Herbicides That Target Acetohydroxyacid Synthase Are Potent Inhibitors of the Growth of Drug-Resistant Candida auris. ACS Infect. Dis. 6, 2901-2912. doi: 10.1021/acsinfecdis.0c00229.

32. Pang SS, Guddat LW, Duggleby RG. (2003) Molecular basis of sulfonylurea herbicide inhibition of acetohydroxyacid synthase. J. Biol. Chem. 278(9):7639-44. doi: 10.1074/jbc.M211648200.

33. Fredrich E, Barzantny H, Brune I, Tauch A. (2013) Daily battle against body odor: Towards the activity of the axillary microbiota. Trends Microbiol. 21, 305-12. doi: 10.1016/j.tim.2013.03.002. 
34. James AG, Austin CJ, Cox DS, Taylor D, Calvert R. (2013) Microbiological and biochemical origins of human axillary odour. FEMS Microbiol. Ecol. 83, 527-40. doi: 10.1111/1574-6941.12054.

35. Taylor D, et al. (2003) Characterization of the microflora of the human axilla. Int. J. Cosmet. Sci. doi: 10.1046/j.1467-2494.2003.00181.x.

36. James AG, Casey J, Hyliands D, Mycock G. (2004) Fatty acid metabolism by cutaneous bacteria and its role in axillary malodour. World J. Microbiol. Biotechnol. 20, 787-93. doi: 10.1007/s11274-004$5843-8$.

37. Zhu M, et al. (2020) Microbial bioconversion of the chemical components in dark tea. Food Chem. doi: 10.1016/j.foodchem.2019.126043.

38. Barbulova A, Colucci G, Apone F. (2015) New trends in cosmetics: By-products of plant origin and their potential use as cosmetic active ingredients. Cosmetics doi: 10.3390/cosmetics2020082.

39. Fujii T, Shinozaki J, Kajiura T, Iwasaki K, Fudou R. (2014) A newly discovered Anaerococcus strain responsible for axillary odor and a new axillary odor inhibitor, pentagalloyl glucose. FEMS Microbiol. Ecol. 89, 198-207. doi: 10.1111/1574-6941.12347.

40. Troccaz M, Starkenmann C, Niclass Y, Van De Waal M, Clark AJ. (2004) 3-methyl-3-sulfanylhexan-1-ol as a major descriptor for the human axilla-sweat odour profile. Chem. Biodivers. doi: $10.1002 / c b d v .200490077$.

41. Kamp F, Kizilbash N, Corkey BE, Berggren PO, Hamilton JA. (2003) Sulfonylureas rapidly cross phospholipid bilayer membranes by a free-diffusion mechanism. Diabetes $52,2526-31$. doi: 10.2337/diabetes.52.10.2526.

42. Kreisberg JF, Ong NT, Krishna A, Joseph TL, Wang J, Ong C, et al. (2013) Growth inhibition of pathogenic bacteria by sulfonylurea herbicides. Antimicrob Agents Chemother. 57, 1513-7. doi: 10.1128/AAC.02327-12.

43. Garcia MD, Wang JG, Lonhienne T, Guddat LW. (2017) Crystal structure of plant acetohydroxyacid synthase, the target for several commercial herbicides. FEBS J. 284, 2037-51. doi: $10.1111 /$ febs. 14102.

44. Jung IP, Cho JH, Koo BS, Yoon MY. (2015) Functional evaluation of residues in the herbicide-binding site of Mycobacterium tuberculosis acetohydroxyacid synthase by site-directed mutagenesis. Enzyme Microb. Technol. 78, 18-26. doi: 10.1016/j.enzmictec.2015.06.009.

45. Kort E, Jovinge S. (2021) Drug Repurposing: Claiming the Full Benefit from Drug Development. Curr. Cardiol. Rep. 23, 62. doi: 10.1007/s11886-021-01484-5.

46. Wen L, Huang B, Tu R, Wan K, Zhang H, Zhang X. (2021) Effectiveness and safety of glibenclamide for stroke: protocol for a systematic review and meta-analysis. BMJ Open 11, e043585. doi: 10.1136/bmjopen-2020-043585.

47. Lowes DJ, Hevener KE, Peters BM. (2020) Second-Generation Antidiabetic Sulfonylureas Inhibit Candida albicans and Candidalysin-Mediated Activation of the NLRP3 Inflammasome. Antimicrob. Agents Chemother. 64, e01777-19. doi: 10.1128/AAC.01777-19. 
48. Lin YW, Liu PS, Pook KA, Wei LN. (2018) Glyburide and retinoic acid synergize to promote wound healing by anti-inflammation and RIP140 degradation. Sci. Rep. 8, 834. doi: 10.1038/s41598-01718785-x.

\section{Tables}

Table 1. Malodor-related metabolites produced by skin bacteria and metabolites in human sweat. 
Bacterial metabolites

\begin{tabular}{|c|c|}
\hline Acetic acid & HMDB0000042 \\
\hline Androstenol (5alpha-Androst-16-en-3alpha-ol) & HMDB0005935 \\
\hline Butyric acid & HMDB0000039 \\
\hline Citric acid & HMDB0000094 \\
\hline Diacetyl & HMDB0003407 \\
\hline 5b-dihydrotestosterone & HMDB0006770 \\
\hline Ethylmethylacetic acid & HMDB0002176 \\
\hline Formic acid & HMDB0000142 \\
\hline Isobutyric acid & HMDB0001873 \\
\hline Isovaleric acid & HMDB0000718 \\
\hline 3-methylindole (Skatole) & HMDB0000466 \\
\hline Oxoglutaric acid & HMDB0000208 \\
\hline Valeric acid & HMDB0000892 \\
\hline \multicolumn{2}{|l|}{ Metabolites in human sweat } \\
\hline Acetoacetic acid & HMDB0000060 \\
\hline L-Alanine & HMDB0000161 \\
\hline Ammonium & HMDB0041827 \\
\hline Fumaric acid & HMDB0000134 \\
\hline Glycerol & HMDB0000131 \\
\hline Glycine & HMDB0000123 \\
\hline L-Histidine & HMDB0000177 \\
\hline L-Isoleucine & HMDB0000172 \\
\hline L-Lactic acid & HMDB0000190 \\
\hline L-Phenylalanine & HMDB0000159 \\
\hline Pyruvic acid & HMDB0000243 \\
\hline Serine & HMDB0062263 \\
\hline L-Tyrosine & HMDB0000158 \\
\hline
\end{tabular}


Table 2. Interactions of sulfonylureas with ALS, respective free energy $(\Delta G)$ and amino acid in ALS binding sites. Chlorimuron ethyl is the positive control which has known as an ALS inhibitor (32).

\begin{tabular}{lll} 
Compounds & $\Delta \mathbf{G}(\mathrm{Kcal} / \mathrm{mol})$ & Amino acid binding sites \\
$\begin{array}{l}\text { Sulfonylureas as herbicides } \\
\text { Chlorimuron ethyl (CE) }\end{array}$ & -6.6 & HIS599 \\
\hline \multicolumn{2}{l}{ Sulfonylureas for diabetes } & \\
\hline Gliquidone (GLQ) & -7.4 & GLN202,PR0114, GLY116 \\
\hline Glisoxepide (GLX) & -6.6 & GLN418, ARG393 \\
\hline Metahexamide (MH) & -6.4 & ILE385, GLN418, VAL416 \\
\hline Tolbutamide (TBM) & -6.3 & TYR595, HIS599 \\
\hline Chlorpropamide (CHL) & -6.1 & HIS599, THR598, TYR595
\end{tabular}

\section{Figures}



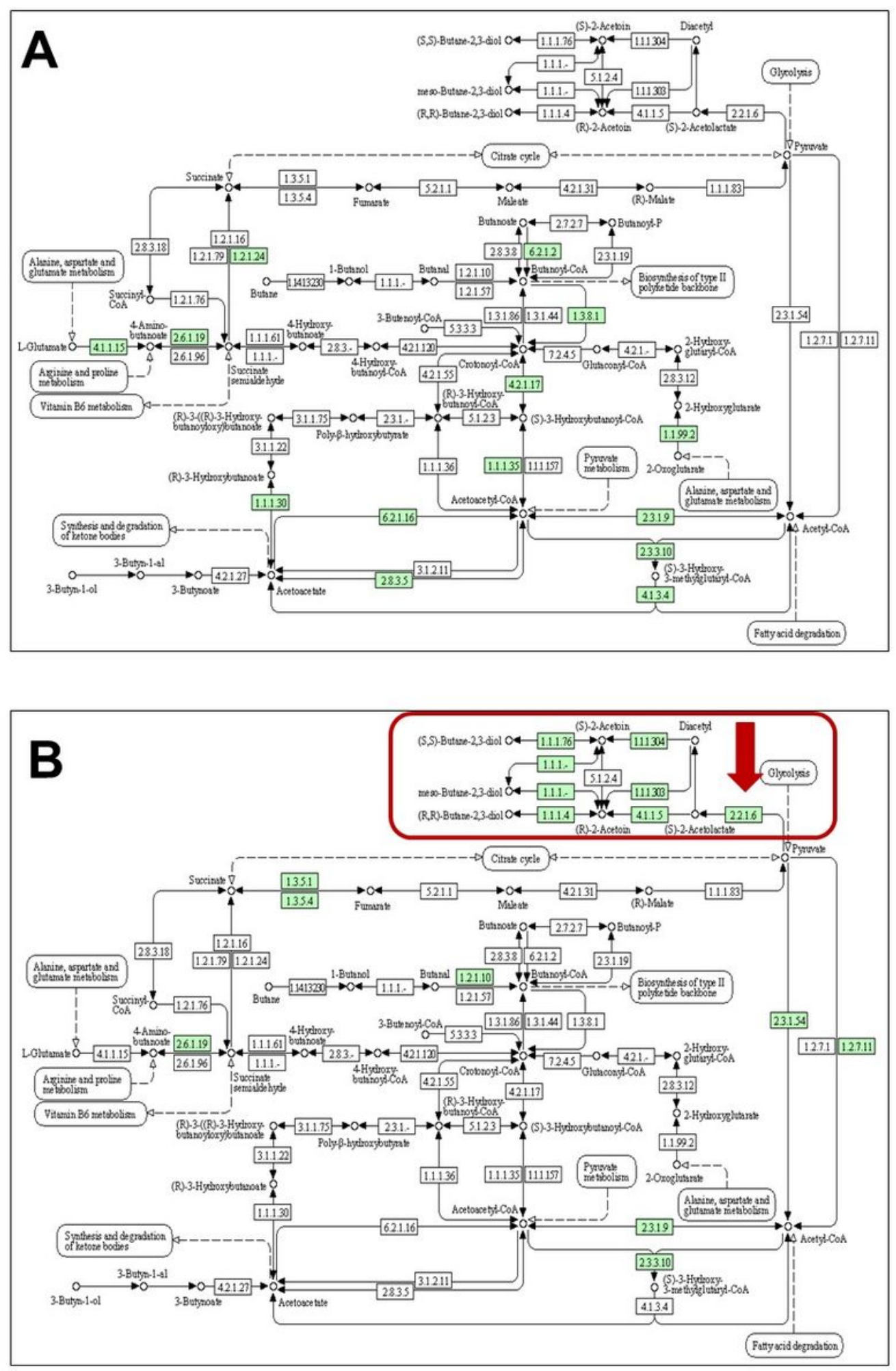

\section{Figure 1}

The KEGG pathways of butanoate metabolism are shown. Enzymes in the common and distinct pathways of butanoate metabolism in homo sapiens (human) (A) and S. epidermidis ATCC 12228 (B) were displayed. After uploading 28 metabolites (Table 1) onto Metaboanalyst version 5.0, enzymes involved in the metabolism of uploaded metabolites were denoted in green boxes. The red box 
highlighted a fermentation pathway for the formation of diacetyl, 2-acetonin, and butane-2,3-diol in $S$. epidermidis. The ALS (EC 2.2.1.6) (red arrow) is an enzyme that converts pyruvate into 2-acetolactate.
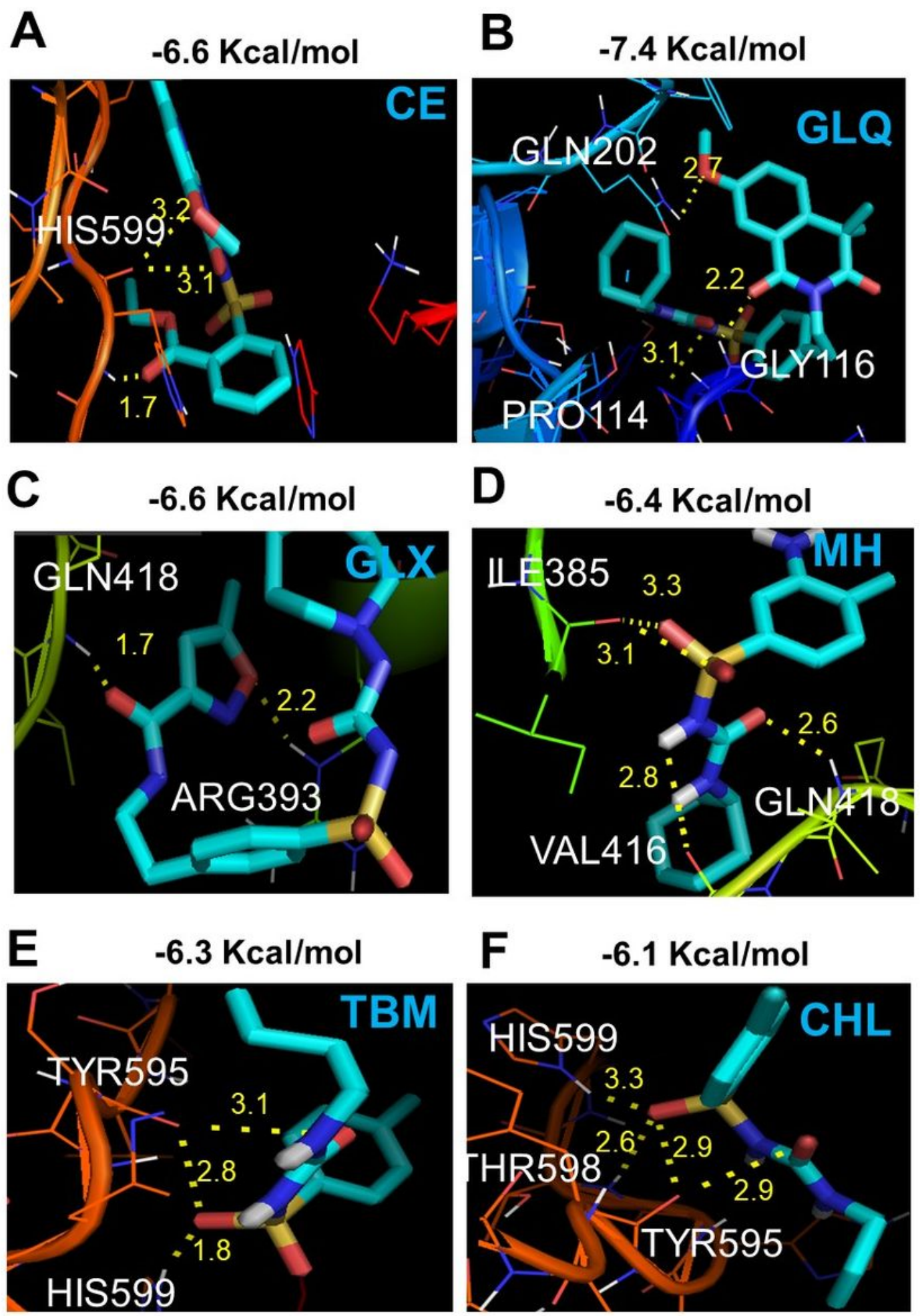

Figure 2

Interaction and free energy $(\Delta G)$ of sulfonylureas with ALS. The stick models (blue) of six sulfonylureas [Chlorimuron ethyl (CE), (A); Gliquidone (GLQ), (B); Glisoxepide (GLX), (C); Metahexamide (MH), (D); 
Tolbutamide (TBM), (E); and Chlorpropamide (CHL), (F)] are presented. The sulfonylurea binding amino acid residues in ALS were revealed in white. The values $(\AA)$ of distances between two binding sites (molecules in sulfonylureas and amino acid residues in ALS) were displayed (yellow). The binding free energy $(\mathrm{Kcal} / \mathrm{mol})$ of the ALS to each sulfonylurea is shown above each panel. 